\title{
Edição independente: um campo de pesquisa em construção
}

\author{
Independent edition: a research field under construction
}

\author{
Edición independiente: un campo de investigación en construcción \\ Flávia Denise de Magalhães* \\ Paula Renata Moreira*
}

Literatura e autoria, edição e editor, livro: palavras e agrupamentos que pertencem ao mesmo campo semântico, foram construídos lentamente e são comumente entendidos como práticas e artefatos antigos, praticamente sinônimos de perenidade. O que é também comum a essas palavras e agrupamentos é a percepção - em análises mais superficiais - de que são construções milenares, surgidas na Antiguidade. Se é possível argumentar que a presunção possa se sustentar ao falarmos de livro, no sentido de conjunto de textos em rolo ou encadernados, e de literatura, no sentido mais amplo, incluindo a tradição oral, o mesmo não se aplica a autoria, edição e editor.

A concepção atual ${ }^{1}$ de edição é consolidada com a mercantilização do livro, após a popularização da prensa de tipos móveis de Gutenberg, no século $\mathrm{XV}$, como expõem em profundidade os historiadores Lucien Febvre e Henry-Jean Martin (2017). Para o historiador Roger Chartier (1998, p. 50-65), as figuras do autor e do editor foram consolidadas bem depois, nos séculos XVIII e XIX, respectivamente.

Acerca da "edição" - uma das palavras que usamos para compor o tema deste dossiê -, temos uma prática com mais de 500 anos. Dada a idade desse procedimento e a extensa lista de obras que sofreram processo de consagração após a necessária etapa editorial, seria compreensível entendê-la como antiga, perene e intrinsecamente ligada a uma noção de legitimação. Isso é, se evitássemos qualquer análise de sua história. A prática da edição é marcada por grandes mudanças, como as ocasionadas pela gradual perda de poder e monopólio da Igreja e da monarquia e a emergência da classe burguesa e sua lógica capitalista, que democratiza o conhecimento e impulsiona um rearranjo social, político e econômico (Bragança, 2005).

Em outras palavras, por vezes o fruto da edição é legitimado e entra para o cânone, mas a edição em si é uma prática marcada por lutas e dificuldades típicas de um negócio, que existe dentro de um mercado, com o agravante de ser um negócio ligado às artes, que impõem regras próprias e muitas vezes contrárias àquelas do capitalismo.

Considerando o desenvolvimento histórico da edição, não é surpreendente a constatação de que a pesquisa em edição seja recente, em especial no Brasil, onde a própria prática da publicação era proibida até $1808 .{ }^{2}$ Quando então direcionamos o olhar para a edição independente, que só começa a surgir a partir da consolidação tanto da prática editorial quanto das figuras de autor e editor, o aspecto histórico mostra-se ainda mais limitado, posto que recente.

\footnotetext{
* Universidade Federal de Minas Gerais (UFMG), Belo Horizonte, MG, Brasil. Dorcid.org/0000-0003-4028-408X. E-mail: flavia.denise@gmail.com

** Centro Federal de Educação Tecnológica de Minas Gerais (Cefet/MG), Belo Horizonte, MG, Brasil. (Dorcid.org/0000-0001-84214898. E-mail: natamoreira@gmail.com

${ }^{1}$ Não por acaso usamos "concepção atual” ao citar as datas. Obviamente, havia criadores para o que chamamos de literatura antes dessa data, mas não eram necessariamente autores no sentido que entendemos hoje. Aplicar o termo à história sem distinguir entre os regimes de existência seria desconsiderar suas nuances. Para se aprofundar na atual compreensão de autor, ver Foucault (2006), Barthes (2004) e Chartier (2014). O mesmo se adota para edição e editor. Livros criados antes da data apontada passaram por processos próprios, mas dada a concepção de edição atual, chamar esse processo de edição acriticamente seria desconsiderar os eventos que revolucionaram não só o livro, como o mundo, a partir das datas apontadas. Para se aprofundar nessa história, ver Fischer (2006).

${ }^{2}$ Data da chegada da família real portuguesa ao país, que trouxe consigo a Impressão Régia e anulou a proibição existente à impressão.
} 
Importante enfatizarmos, mesmo que brevemente, o independente - a outra palavra que usamos para compor o tema deste dossiê. É um termo de significado intuitivo claro, que remete à autonomia, à liberdade criativa e a uma oposição a algo, mas que desaparece entre suas muitas camadas quando há tentativas de defini-lo satisfatoriamente. ${ }^{3}$ Para uma visão panorâmica, possivelmente seja mais interessante salientarmos a posição e oposição daqueles que se declaram "independentes" aos campos literário e editorial.

As lutas de definição (ou de classificação) têm como aposta fronteiras (entre os gêneros ou as disciplinas, ou entre os modos de produção no interior de um mesmo gênero), e, com isso, hierarquias. Definir as fronteiras, defendê-las, controlar as entradas, é defender a ordem estabelecida no campo. Com efeito, o aumento do volume da população dos produtores é uma das mediações principais através das quais as mudanças externas afetam as relações de força no seio do campo: as grandes alterações nascem da irrupção de recém-chegados que, apenas como resultado de seu número e de sua qualidade social, introduzem inovações em matéria de produtos ou de técnicas de produção, e tendem a impor ou pretendem impor em um campo de produção que é para si mesmo seu próprio mercado, um novo modo de avaliação dos produtos (Bourdieu, 1996, p. 255).

A observação do sociólogo - sobre as lutas pela definição de fronteiras dentro de um campo, sobre disputas pelo poder de definir o que é parte do campo e o que não pode ser considerado como parte dele, sobre a possibilidade de criar e impor modos próprios de produção, de avaliação de produtos e de valoração - dá uma noção não do que significa o termo independente, mas de seu regime de existência, marcado pela tomada de posição, pela oposição e pela luta pelo poder de definição das regras do campo.

Essas lutas são próprias desse espaço, não sendo restritas ao chamado "independente". A questão aqui é que o independente parece reconhecer essas disputas como característica fundadora de um modo de fazer, enquanto aqueles agentes que ocupam posição central no campo editorial - que observamos ser formado por diversos microcampos - tendem a trabalhar pelo apagamento de conflitos e pela consolidação de um poder de definição que já lhes pertence.

Assim, propor a temática da edição independente para este dossiê é intentar reunir pesquisas sobre um tema cuja historiografia ainda está sendo escrita. É trazer à tona pontos nodais do dito campo editorial, que é definido por sua dupla natureza - mercantil e literária (Bourdieu, 2018) -, suas lutas por definição, bem como pelo poder de consagração. É sugerir um recorte do campo editorial cujas fronteiras são tão intuitivamente claras quanto conceitualmente elusivas. No entanto, propor edição independente como tema deste dossiê é também reconhecer a existência de um movimento contínuo, que ganha força. É observar que a irrupção de recém-chegados aos campos editorial e literário é volumosa, introduz inovações e propõe grandes alterações que estão em linha não somente com questões da edição ou da literatura, mas com profundas mudanças da sociedade, como a globalização, a tecnologia digital e o excesso de informação.

O conjunto de textos que passou pelo crivo da seleção da revista Estudos de Literatura Brasileira Contemporânea reflete algo da complexidade por trás do que entendemos como edição independente.

Em "Padê Editorial e Nega Lilu: representatividade feminina no mercado", são apresentadas as práticas de duas casas editoriais do campo independente, ambas dirigidas por mulheres. No caso da Padê, a construção do catálogo é orientada para a publicação de mulheres lésbicas, bissexuais, transsexuais e transgêneros, com especial atenção para a autoria negra. Já a Nega Lilu opta por uma prática de descentralização. Situada em Goiânia, sua editora, Larissa Mundim, age para a visibilização de produtores fora do eixo Rio-São Paulo, especialmente aqueles localizados em Goiás.

Já no artigo "Editoras cartoneras e a literatura fora do cânone: um olhar crítico para as margens do mundo editorial", traça-se um panorama da rede internacional de editoras cartoneras, a partir de Eloísa Cartonera. As editoras cartoneras, como se sabe, produzem livros a partir de papelão descartado, agindo, com sua prática, para ressituar a questão do consumo, da sustentabilidade e, mais amplamente, do próprio fazer editorial.

\footnotetext{
${ }^{3}$ Para se aprofundar no termo "independente" e seu significado, ver Araújo (2013) e Muniz (2016).
} 
"Livros do Mal: da publicação virtual à autolegitimação editorial" tem como foco a editora porto-alegrense, com relato de seu histórico a partir do e-zine CardosOnline e uma breve revisão dos nove títulos publicados pela casa editorial. Criada por um grupo jovem, à época sem espaço em casas consolidadas do campo, a Livros do Mal é um experimento de autopublicação que conseguiu legitimar seus autores no campo.

Em "Livros para infâncias diversas: casos de editoras independentes da Argentina e do Brasil", a questão fulcral da edição independente - a bibliodiversidade - encontra o tópico da diversidade sexual. Analisam-se, então, projetos de editoras independentes argentinas e brasileiras cujas produções enfatizam as questões de gênero - especialmente a temática trans voltadas para público infantil.

"Redes da literatura em portunhol: existência e pluralidade como expressão da fronteira", por sua vez, traz à cena as redes latinoamericanas para pensar a experiência da fronteira. Por meio das obras Triple frontera dreams (2012), do escritor brasileiro Douglas Diegues, Xirú (2010), do paraguaio Damián Cabrera, e Viralata (2015) do uruguaio Fabián Severo, avalia-se o portunhol como recurso literário e as publicações por meio de editoras independentes.

Em "Por una sociología del espacio editorial: el caso de César Aira y Beatriz Viterbo", a trajetória do escritor César Aira é pensada em relação à sua consagração, especialmente relacionada à existência da editora Beatriz Viterbo. Para a discussão, parte-se da sociologia da literatura e da relação entre espaços regidos por lógicas diferentes: a academia e o mercado editorial.

Por fim, "O livro como forma de arte: a contribuição de Julio Plaza na produção e teorização do livro de artista no Brasil" apresenta e analisa a contribuição de Julio Plaza ao entendimento brasileiro de marginal (aqui entendido como independente) e à conceituação e teoria do livro de artista. Caminhando na fronteira entre arte, literatura e edição, o livro de artista é um exemplo de produção feita fora da lógica do mercado e que, não raro, é reconhecida e aclamada pelo campo.

Não há dúvidas. A criação, a edição e a circulação da literatura brasileira dita "independente" passam por um momento de efervescência - ou pelo menos assim se encontrava imediatamente antes do advento da pandemia do novo coronavírus. $\mathrm{O}$ crescente número de autores autopublicados, editoras de pequeno porte e encontros dedicados ao livro e à literatura, como feiras, festas e festivais literários, são indícios de uma movimentação profunda no campo editorial. Em que pese o arrefecimento dos eventos ligados a aglomerações, a cena permanece criativa e em movimento. Tal conjuntura possibilita o surgimento de espaços, tanto para publicação quanto para recepção, de autores e obras que não estão em conformidade com as práticas mais estabelecidas do mercado editorial. Esse não é um universo temporário, mas contínuo, em que lutas de definição espelham e marcam o caminhar da humanidade.

\section{Referências}

ARAÚJO, Pablo Guimarães (2013). Uma tecnologia na mão e uma ideia na cabeça: pequenas editoras, autores independentes e as novas possibilidades de publicação de livros. Dissertação (Mestrado em Estudos de Linguagens) - Centro Federal de Educação Tecnológica de Minas Gerais, Belo Horizonte.

BARTHES, Roland (2004). A morte do autor. In: BARTHES, Roland. O rumor da língua. 2. ed. São Paulo: Martins Fontes. p. 57-64.

BOURDIEU, Pierre (1996). As regras da arte: gênese e estrutura do campo literário. Tradução de Maria Lucia Machado. São Paulo: Companhia das Letras.

BOURDIEU, Pierre (2018). Uma revolução conservadora na edição. Tradução de Luciana Salazar Salgado e José de Souza Muniz Júnior. Política E Sociedade, Florianópolis, v. 17, n. 39, p. 198-249, maio/ago.

BRAGANÇA, Aníbal (2005). Sobre o editor: notas para sua história. Em Questão, Porto Alegre, v. 11, n. 2, p. 219-237, jul./dez.

CHARTIER, Roger (1998). A aventura do livro: do leitor ao navegador - Conversações com Jean Lebrun. Tradução de Reginaldo Carmello Corrêa de Moraes. São Paulo: Unesp. 
CHARTIER, Roger (2014). O que é um autor? Revisão de uma Genealogia. Tradução de Luzmara Curcino e Carlos Eduardo Bezerra. São Carlos: Edufscar.

FEBVRE, Lucien; MARTIN, Henry-Jean (2017). O aparecimento do livro. Tradução de Fulvia M. L. Moretto e Guacira Marcondes Machado. São Paulo: Edusp.

FISCHER, Steven Roger (2006). História da Leitura. Tradução de Cláudia Freire. São Paulo: Unesp.

FOUCAULT, Michel (2006). O que é um autor. In: FOUCAULT, Michel. Estética: literatura e pintura, música e cinema. São Paulo: Forense. p. 264-298.

MUNIZ JÚNIOR, José de Souza. Girafas e bonsais: editores “independentes" na Argentina e no Brasil (19912015). Tese (Doutorado em Sociologia) - Universidade de São Paulo, São Paulo. 